National Water Quality Program

\title{
Considerations for Incorporating Quality Control Into Water Quality Sampling Strategies for the U.S. Geological Survey
}

Open-File Report 2020-1109 



\section{Considerations for Incorporating Quality Control Into Water Quality Sampling Strategies for the U.S. Geological Survey}

By Laura Medalie

National Water Quality Program

Open-File Report 2020-1109 


\title{
U.S. Department of the Interior \\ DAVID BERNHARDT, Secretary
}

\author{
U.S. Geological Survey \\ James F. Reilly II, Director
}

U.S. Geological Survey, Reston, Virginia: 2020

For more information on the USGS - the Federal source for science about the Earth, its natural and living resources, natural hazards, and the environment—visit https://www.usgs.gov or call 1-888-ASK-USGS.

For an overview of USGS information products, including maps, imagery, and publications, visit https://store.usgs.gov/.

Any use of trade, firm, or product names is for descriptive purposes only and does not imply endorsement by the U.S. Government.

Although this information product, for the most part, is in the public domain, it also may contain copyrighted materials as noted in the text. Permission to reproduce copyrighted items must be secured from the copyright owner.

Suggested citation:

Medalie, L., 2020, Considerations for incorporating quality control into water quality sampling strategies for the U.S. Geological Survey: U.S. Geological Survey Open-File Report 2020-1109, 5 p., https://doi.org/10.3133/ ofr20201109.

ISSN 2331-1258 (online) 


\section{Contents}

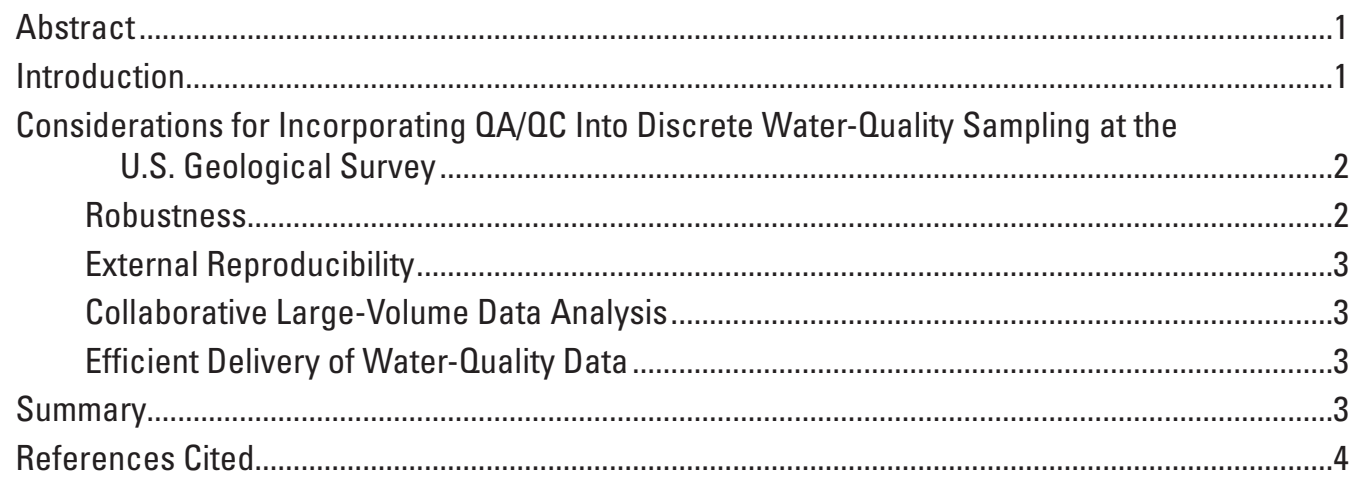

\section{Abbreviations}

$\begin{array}{ll}\text { NWIS } & \text { National Water Information System } \\ \text { NWOL } & \text { National Water Quality Laboratory } \\ \text { OA/OC } & \text { quality assessment and quality control } \\ \text { OC } & \text { quality control } \\ \text { OSB } & \text { Quality Systems Branch } \\ \text { USGS } & \text { U.S. Geological Survey }\end{array}$





\title{
Considerations for Incorporating Quality Control Into Water Quality Sampling Strategies for the U.S. Geological Survey
}

\author{
By Laura Medalie
}

\section{Abstract}

This report describes considerations for incorporating routine quality-assessment and quality-control evaluations into U.S. Geological Survey discrete water-sampling programs and projects. U.S. Geological Survey water-data science in 2020 is characterized by robustness, external reproducibility, collaborative large-volume data analysis, and efficient delivery of water-quality data. Confidence in data, or robustness, can be increased by supplementing traditional field-based quality-control data with laboratory quality control (QC) data, such as third-party blind spikes and blind blanks, laboratory blanks, and laboratory-reagent spikes. Laboratory qualitycontrol data can provide additional information about bias and variability, method performance, and false-positive and false-negative rates that are not available from field QC data alone. Reproducibility is supported by means of standardizing metadata and documentation. Collaborative analysis brings together disparate elements of various types of qualitycontrol review and communicates persistent data quality issues for compounds to data users internal and external to the U.S. Geological Survey. Efficient delivery of water-quality data is achieved when quality-control review is accomplished in the same expedited (near real-time) time frame as distribution of environmental results to the public and might be improved with consideration given to data versioning or to a system of alerting data users to data interpretation that might differ from originally published data.

\section{Introduction}

The Water Science Strategy for the U.S. Geological Survey (USGS) explains that acknowledgment of uncertainty in water science goes along with proficiency in the work that USGS does (Evenson and others, 2013). The Science Strategy specifies that the USGS will make a strategic effort to estimate or quantify uncertainty associated with its information products. Since the inception of the National Water-Quality Assessment (NAWQA) Project in 1991, the USGS has developed, applied, and documented a number of approaches to quantify uncertainty in water-quality results. Standard protocols for assessment of quality of chemical results of water samples reported by the National Water Quality Network include timely review of all environmental and field quality control (QC) results and metadata for accuracy, including assessment of outliers and contextual reasonableness (Riskin and others, 2018). Examples of additional QC interpretations that have been done on an irregular basis, usually by large and long-term USGS projects like the NAWQA project or the Groundwater Ambient Monitoring and Assessment (GAMA) Program Priority Basin Project, include evaluations of long-term and collective (1) field-blank results to determine potential bias from nonlaboratory-derived contamination over time (Medalie and Martin, 2016; Mueller and Titus, 2005), (2) field replicate results to quantify variability over time (Martin, 2002; Mueller and Titus, 2005) and (3) field matrix spike and laboratory reagent spike results (Shoda and others, 2018; Martin and others, 2009). Most of these approaches are described in detail by Mueller and others (2015).

Historic approaches to QC water-quality data assessments were based solely on field QC samples; recent approaches supplement field QC with laboratory QC samples (Medalie and others, 2019; Bexfield and others, 2020). As approaches toward conducting science and delivering products at the USGS evolve, it is essential that the concomitant approaches to assessing and reporting on the quality of the data also evolve. A systematic strategy for review of long-term QC datasets needs to be incorporated into future USGS water-quality programs and projects. The purpose of this report is to discuss generalized considerations for incorporating quality assurance/quality control (QA/QC) into long-term discrete water sampling programs and projects at the USGS. 


\section{Considerations for Incorporating QA/OC Into Discrete Water-Quality Sampling at the U.S. Geological Survey}

QA/QC science for discrete water-quality sampling continues to evolve with concomitant changing goals and tools identified by the USGS for the generation of scientific data. Important needs that increasingly characterize USGS waterdata science include (1) robustness, (2) external reproducibility, (3) collaborative large-volume data analysis, and (4) efficient delivery of water-quality data (U.S. Geological Survey, 2019). The successful utilization of these data-science tools requires that traditional QC tools and practices that support and document environmental data quality need to be updated, documented, communicated, and automated.

\section{Robustness}

Robustness means that QA/QC instills confidence that water-quality data are used appropriately in interpretive studies. Confidence is generated by provision of quantitative measures of uncertainty: confidence intervals for a mean or median, confidence limits for a percentile or proportion, false-positive and false-negative rates, or uncertainty or variability expressed as imprecision or error (Mueller and others, 2015). Periodic review of long-term field QC information to assess bias and variability has been a hallmark of longterm USGS programs such as the National Water Quality Assessment Project and the Groundwater Ambient Monitoring and Assessment Program Priority Basin Project, but review of long-term laboratory QC information did not become part of some USGS project protocols (as distinguished from internal reviews routinely conducted by the National Water Quality Laboratory [NWQL] and Quality Systems Branch [QSB]) until recent years (Bexfield and others, 2019, 2020; Medalie and others, 2019; Medalie and Bexfield, 2020).

Information about bias and variability in field QC samples reflects laboratory (as well as sample collection, storage, and shipment) processes; however, it is not possible to separate laboratory-related bias and variability from fieldrelated bias and variability without QC data from the NWQL and QSB. For example, laboratory QC data from QSB thirdparty samples (such as blind spikes and blind blanks from the Inorganic Blind Sample Project and the Organic Blind Sample Project) provide information about recovery bias and variability, false-positive and false-negative rates, and method performance over time. Recovery data from blind spikes can reveal low or high biases or high variability in reported water-quality results. Recovery is the measured amount of the compound in a spiked sample expressed as a percentage of the amount spiked, ideally 100 percent, and a recovery bias is identified when the median recovery percentage for a given compound over a period of time is outside of a target range (Martin and others, 2009; Shoda and others, 2018). False-positive and false-negative rates from QSB samples can be compared with rates deemed acceptable for project-specific objectives and can provide important metadata for interpretations of environmental data. Results from blind samples contribute information about method performance because these samples are subject to the same laboratory processes as environmental samples.

NWQL laboratory blank and laboratory reagent spike datasets also provide important information for a comprehensive assessment of the quality of environmental water-quality data. Laboratory blanks can be used to identify episodic and random laboratory contamination not addressed by set censoring (Medalie and others, 2019; Bexfield and others, 2020). Laboratory reagent spikes supplement information from field QC and QSB samples about recovery bias and overall method performance and can help identify specific quality issues that occasionally arise, such as the degradation of target compounds in spike solutions (Shoda and others, 2018).

Reviews of laboratory QC datasets should be structured to assess environmental relevance in time and space, basically the "inference space" as described by Mueller and others (2015). An inference space for QC includes the spatial and temporal conditions under which QC samples can be related to environmental samples because the QC results reflect the same conditions, in terms of potential bias and variability, under which the environmental samples were collected. Biased or highly variable results often occur in discrete episodes of time that do not correspond to calendar constructs (that is, months or years), such as from inadvertent use of contaminated laboratory vials or spike solutions. A relevant way to address discrete episodes of issues with data quality is to target qualifications or corrective action to environmental data that coincide with the episode, that is, not to extend those actions beyond the need. For instance, in Medalie and Bexfield (2020), periods of bias and variability are identified on the basis of water years ${ }^{1}$ for expediency, whereas in many other cases, the periods with uncertain quality are less than complete years. In those cases, another approach might be to calculate a moving average that identifies time periods during which a given condition indicative of contamination bias (such as detection frequency greater than 10 percent in laboratory blanks) prevails (Fram and Belitz, 2011; Medalie and others, 2019). Similarly, method-performance issues illustrated by recovery bias can exhibit patterns in time that span multiple years or that frequently alternate between high and low biases (Shoda and others, 2017).

\footnotetext{
${ }^{1} \mathrm{~A}$ water year is defined as the 12 -month period extending from October 1 of any given year through September 30 of the following year and is designated by the calendar year in which it ends.
} 


\section{External Reproducibility}

Reproducibility of findings is largely addressed by adequate documentation of methods and interpretations, along with accessible information. Documentation is the foundation of QA/QC. Tools and techniques that ensure robust and efficient production of environmental data are of little use without adequate documentation. The fundamental science practices at the USGS for scientific-data management require scientists to place all reviewed and interpreted datasets, along with a complete metadata record, in a permanent, trusted repository (U.S. Geological Survey, 2017).

\section{Collaborative Large-Volume Data Analysis}

Collaborative analysis in a $\mathrm{QC}$ context means designing a system to bring together and provide access to disparate elements of data review. For example, currently [2020], the primary mechanism for distributing results or interpretations from QC analyses after data publication is to publish the description in a report or paper and the data used for the interpretation in a data release. If different data analysts are interested in using that same dataset for other studies, they might not be aware that the data published in the public National Water Information System (NWIS) portal (U.S. Geological Survey, 2020) have been interpreted and that a modified dataset is available (which dataset is preferable is another question). There is no mechanism or system to routinely communicate data-quality issues identified from interpretations of published data.

Medalie and Bexfield (2020) describe several triggers for flagging individual results in NWIS or for flagging compounds from the analysis of this report. For example, individual results for 19 compounds were marked with a permanent "E" remark code for quantified results because data-quality objects were not met during validation. Data users, especially non-USGS users who are less likely to be familiar with NWIS water-quality metadata, might not be aware that various qualifier codes or interpretations described in reports such as Medalie and Bexfield (2020) could be important for data analysis. More accessible metadata that communicates QC interpretations as a standard accompaniment to published water-quality results is an important way to move USGS data science forward.

\section{Efficient Delivery of Water-Quality Data}

The identification of datasets and techniques for improving robustness needs to be accompanied by efficient implementation of data review and vetting techniques. The importance of providing water-quality results to the public in relevant timeframes is emphasized on the national level (U.S. Geological Survey, 2019), and a corollary is needed to produce $\mathrm{QC}$ review in the same expedited timeframe. Data review would benefit from routine publication of QC datasets from the QSB and NWQL rather than made available by request. To the extent feasible, review procedures for waterquality QC data that adhere to USGS policies and meet the needs of data users can be automated. For example, versioning of water-quality data is one approach that could allow for the competing needs of providing quick delivery of data to the public as well as providing data that are more thoroughly vetted after review of long-term QC datasets. If data versioning is not possible, best practices might include provision of relevant citations to products that interpret or analyze related datasets through the same process that serves water-quality results.

QC data can be evaluated at various stages of reporting results. Although it would be preferable in some respects to schedule all QC reviews before the publication of waterquality data, either at the NWQL before preliminary results are sent to water science centers for review or during preliminary review by data analysts at water science centers, current [2020] protocols allow environmental results to be published after water science center review and before review of longterm datasets (Medalie and others, 2019, fig. 1). The reasons for this discrepancy in review and publication include the expectations of data users to get analytical results as quickly as possible and the intrinsic retroactive nature of reviewing long-term datasets. With the goal of increasing efficiency, opportunities for implementing review in a real-time or near real-time environment should be identified. One action that could be taken at the NWQL before production of preliminary results is to develop an automated protocol to flag detections in different types of laboratory blanks (blind blanks or laboratory blanks in sets in the same batch or in other sets analyzed close in time), which might help to address random laboratory contamination before results are published. Other opportunities for developing systematic (integrated and automated) routines for review of long-term datasets are numerous.

\section{Summary}

Characteristics of U.S. Geological Survey (USGS) water data science include (1) robustness, (2) external reproducibility, (3) collaborative large-volume data analysis, and (4) efficient delivery of water-quality data. Robustness means that a suite of quality control and quality assurance (QA/QC) samples provides confidence that environmental water-quality data meet data-quality objectives for specific uses. Laboratory quality control (QC) results, historically not evaluated as part of standard USGS protocols, can supplement field QC results by providing information about more targeted types of biases and variability. Blind spikes and blind blank samples from the USGS Quality Systems Branch (QSB), for example, provide information about recovery bias and variability for specific methods of data analysis, as well as false-positive and falsenegative rates, and method performance over time. Laboratory blanks from the National Water Quality Laboratory identify episodic and random laboratory contamination not addressed 
by set censoring, and laboratory reagent spikes supplement information from field QC and QSB samples about recovery bias and overall method performance.

Reproducibility involves documentation and accessible information. Collaborative science requires coordinated communication of all aspects of QA/QC interpretations as a standard accompaniment to published water-quality results. Automation of $\mathrm{QA} / \mathrm{QC}$ review processes would help ensure that integrated QA/QC documentation is available within the same expedited time frame as the distribution of environmental results to the public. Data versioning or a system to alert data users to results of data interpretation (qualification, removal, or changes to the data) that might affect various uses of that data is an important consideration. Systems to bring together disparate elements of various types of QA/QC review and to communicate persistent data-quality issues for compounds are warranted.

\section{References Cited}

Bexfield, L.M., Belitz, K., Sandstrom, M.W., Beaty, D., Medalie, L., Lindsey, B.D., and Nowell, L.H., 2020, Quality of pesticide data for groundwater analyzed for the National Water-Quality Assessment Project, 2013-18: U.S. Geological Survey Scientific Investigations Report 2020-5072, 35 p., accessed July 27, 2020, at https://doi.org/ 10.3133/sir20205072.

Bexfield, L.M., Toccalino, P.L., Belitz, K., Foreman, W.T., and Furlong, E.T., 2019, Hormones and pharmaceuticals in groundwater used as a source of drinking water across the United States: Environmental Science \& Technology, v. 53, no. 6, p. 2950-2960. [Also available at https://doi.org/ 10.1021/acs.est.8b05592.]

Evenson, E.J., Orndorff, R.C., Blome, C.D., Böhlke, J.K., Hershberger, P.K., Langenheim, V.E., McCabe, G.J., Morlock, S.E., Reeves, H.W., Verdin, J.P., Weyers, H.S., and Wood, T.M., 2013, U.S. Geological Survey water science strategy - Observing, understanding, predicting, and delivering water science to the nation: U.S. Geological Survey Circular 1383-G, 49 p. [Also available at https://doi.org/ 10.3133/cir1383G.]

Fram, M.S., and Belitz, K., 2011, Occurrence and concentrations of pharmaceutical compounds in groundwater used for public drinking-water supply in California: Science of the Total Environment, v. 409, no. 18, p. 3409-3417. [Also available at https://doi.org/10.1016/j.scitotenv.2011.05.053.]
Martin, J.D., 2002, Variability of pesticide detections and concentrations in field replicate water samples collected for the National Water-Quality Assessment Program, 1992-97: U.S. Geological Survey Water-Resources Investigations Report 01-4178, 102 p., accessed September 3, 2019, at https://doi.org/10.3133/wri20014178.

Martin, J.D., Stone, W.W., Wydoski, D.S., and Sandstrom, M.W., 2009, Adjustment of pesticide concentrations for temporal changes in analytical recovery, 1992-2006: U.S. Geological Survey Scientific Investigations Report 2009-5189, 23 p., apps. [Also available at https://doi.org/ 10.3133/sir20095189.]

Medalie, L., and Bexfield, L.M., 2020, Quality of data from the U.S. Geological Survey National Water Quality Network for water years 2013-17: U.S. Geological Survey Scientific Investigations Report 2020-5116, 21 p., https://doi.org/10.3133/sir20205116.

Medalie, L., and Martin, J.D., 2016, Nutrient and pesticide contamination bias estimated from field blanks collected at surface-water sites in U.S. Geological Survey water-quality networks, 2002-12: U.S. Geological Survey Scientific Investigations Report 2016-5129, 40 p., accessed July 16, 2020, at https://doi.org/10.3133/sir20165129.

Medalie, L., Sandstrom, M.W., Toccalino, P.L., and Foreman, W.T., ReVello, R.C., Bexfield, L.M., and Riskin, M.L., 2019, Use of set blanks in reporting pesticide results at the U.S. Geological Survey National Water Quality Laboratory, 2001-15: U.S. Geological Survey Scientific Investigations Report 2019-5055, 147 p., accessed July 16, 2020, at https://doi.org/10.3133/sir20195055.

Mueller, D.K., Schertz, T.L., Martin, J.D., and Sandstrom, M.W., 2015, Design, analysis, and interpretation of field quality-control data for water-sampling projects: U.S. Geological Survey Techniques and Methods, book 4, chap. C4, 54 p., accessed July 16, 2020, at https://doi.org/ $10.3133 / \mathrm{tm} 4 \mathrm{C} 4$.

Mueller, D.K., and Titus, C.J., 2005, Quality of nutrient data from streams and ground water sampled during water years 1992-2001: U.S. Geological Survey Scientific Investigations Report 2005-5106, 27 p., accessed September 3, 2019, at https://doi.org/10.3133/sir20055106.

Riskin, M.L., Reutter, D.C., Martin, J.D., and Mueller, D.K., 2018, Quality-control design for surface-water sampling in the National Water-Quality Network: U.S. Geological Survey Open-File Report 2018-1018, 15 p., accessed July 15, 2020, at https://doi.org/10.3133/ofr20181018. 
Shoda, M.E., Nowell, L.H., Bexfield, L.M., Sandstrom, M.W., Stone, W.W., 2017, Recovery data for surface water, groundwater and lab reagent samples analyzed by the USGS National Water Quality Laboratory schedule 2437, water years 2013-15: U.S. Geological Survey data release, accessed July 16, 2020, at https://doi.org/10.5066/ F7QZ28G4.

Shoda, M.E., Nowell, L.H., Stone, W.W., Sandstrom, M.W., and Bexfield, L.M., 2018, Data analysis considerations for pesticides determined by National Water Quality Laboratory schedule 2437: U.S. Geological Survey Scientific

Investigations Report 2018-5007, 458 p., accessed July 16, 2020, at https://doi.org/10.3133/sir20185007.
U.S. Geological Survey, 2017, 502.8-Fundamental science practices; review and approval of scientific data for release: U.S. Geological Survey Survey Manual web page, accessed January 8, 2020, at https://www.usgs.gov/ about/organization/science-support/survey-manual/5028fundamental-science-practices-review-and.

U.S. Geological Survey, 2019, Data science for water resources: U.S. Geological Survey web page, accessed September 25, 2019, at https://www.usgs.gov/mission-areas/ water-resources/science/data-science-water-resources.

U.S. Geological Survey, 2020, USGS water data for the nation: U.S. Geological Survey National Water Information System database, accessed June 24, 2020, at https://doi.org/ 10.5066/F7P55KJN. 

For more information about this report, contact: Director, New England Water Science Center

U.S. Geological Survey

10 Bearfoot Road

Northborough, MA 01532

dc_nweng@usgs.gov

or visit our website at

https://www.usgs.gov/centers/new-england-water

Publishing support provided by the

Pembroke Publishing Service Center 
